\title{
Association between Fatigue Level with Disease Severity in Myasthenia Gravis Patients
}

\author{
Dimas Pambudi ${ }^{1}$, Fadil ${ }^{2}$, Muhammad Hamdan ${ }^{3}$ \\ ${ }^{1}$ Resident, Department of Neurology, Faculty of Medicine Universitas Airlangga, Dr. Soetomo Public Hospital, \\ Surabaya Indonesia; ${ }^{2}$ Division of Neurophysiology, Department of Neurology, Faculty of Medicine Universitas \\ Airlangga, Dr. Soetomo Public Hospital, Surabaya Indonesia; ${ }^{3}$ Division of Neurobehavior, Department of \\ Neurology, Faculty of Medicine Universitas Airlangga, Dr. Soetomo Public Hospital, Surabaya Indonesia
}

\begin{abstract}
Background: Fatigue is a common symptom and has a greater effect on daily living of myasthenia gravis (MG) patients than has muscle weakness. Latest evidence suggested that fatigue in MG negatively impact disease severity. The relationship between fatigue level with disease severity has never been explored in MG patients. Aims. The study aimed to determine the association between fatigue level and disease severity in myasthenia gravis patients at Dr. Soetomo Public Hospital Surabaya. Method. A cross-sectional was used in this research. Participants of the research were patients with myasthenia gravis in Neurology Clinic, Dr. Soetomo Public Hospital Surabaya. The period of data collection was from April to June 2021. Fatigue level measured with Fatigue Severity Scale (FSS) questionaire and disease severity measured with Myasthenia Gravis Composite (MGC) score. Data analysed using SPSS version 22.0 with significances of $\mathrm{p}<0.05$. Results. There were 37 participants consisted of 14 males and 23 females. Mean age of participants 45,03 $\pm 11,69$. Mean age of onset was 40,38 $\pm 12,60$. The mean FSS was 4,02 $\pm 1,93$ and mean MGC was 5,24 \pm 5,64. From all participants, we found that about 24 patients $(64,9 \%)$ showed severe fatigue and 22 patients $(58,5 \%)$ have severe disease status. The Chi-Square correlation test analysis indicates a significant association between FSS mean score and MGC mean score $(p=0.009$, OR at 6,750) 95\% CI $(1,51-30,16)$. Conclusion. There was an association between fatigue level and disease severity in myasthenia gravis patients.
\end{abstract}

Keywords: Fatigue Level; FSS; Diasease Severity; MGC; Myasthenia Gravis.

\section{Introduction}

Myasthenia gravis (MG) is an autoimmune disease caused by IgGautoantibodies that attack the acetylcholine, MuSK, or LRP4 receptors on neuromuscular junction (NMJ) postsynaptic membrane with typical symptoms of fatigue and fluctuated skeletal muscle weakness

\section{Corresponding author:}

\section{Dimas Pambudi}

Faculty of Medicine, Universitas Airlangga, Surabaya, Indonesia, Campus A, Jl. Mayjen Prof. Dr. Moestopo 47, Surabaya, Indonesia (Zip Code: 60131), dr.dimpam@gmail.com; Telp:+6281232999500 that worsens with activity and improves after rest. The incidence of MG is estimated to be 8-10 cases per 1,000,000 population per year with a prevalence of 150 - 250 per $1,000,000$ population ${ }^{1}$. Based on the 2010 Basic Health Research report, the incidence of MG in Indonesia it is estimated that 1 case out of 100,000 people ${ }^{2}$. Symptoms of MG are very varies with initial symptoms of ptosis and/or diplopia in $85 \%$ of patients and progresses to generalized MG within 2 years of onset in $80 \%$ of cases $^{3}$. Respiratory muscles can be affected in up to $20 \%$ of cases of acetylcholine receptorassociated MG (AChR MG) causing a myasthenic crisis and requiring assistance ventilator ${ }^{4}$. MG-related health economic costs in 8 countries spanning 4 continents (Europe, North America, South America and Asia) 
shows that per year direct medical costs estimated at 760 - 28,780 USD, home care costs between 2,550 - 164,730 USD and indirect costs estimated at $80-3,550$ USD $^{5}$.

Current growing evidence suggests fatigue is a symptom which is common and has a greater effect than muscle weakness in MG patients in daily life. Even MG patients who have been in permanent remission experiencing symptoms of fatigue ${ }^{6}$. Fatigue is a symptom that is getting interesting to study on neuromuscular disorders and their several studies of fatigue in $\mathrm{MG}$ indicate an increased awareness of the importance of these symptoms. Fatigue is a subjective symptom of physical fatigue and/or mental, extreme and persistent weakness or depletion of energy ${ }^{7}$. Fatigue can be classified as peripheral fatigue with disturbances in the components of the motor unit and central fatigue originating from disorders of the central nervous system. Another type of fatigue is physical fatigue and mental fatigue which central fatigue contains both types of fatigue as the main features ${ }^{8}$. In this study, researchers followed the latest taxonomy related to the use of the term fatigue which refers to the subjective sensation of tiredness and fatigability show objective changes in muscle and cognitive performance ${ }^{9}$.

Fatigue is a complex, non-specific and subjective symptom making it difficult to evaluate and measure. Fatigue in MG is peripheral fatigue, however studies show that MG patients also experience cognitive and mental fatigue and significantly more than healthy individuals as controls. Prevalence fatigue in myasthenia gravis is estimated to be between $75 \%$ to $89 \%{ }^{9}$. Assessment of fatigue usually relies on patient selfreport questionnaires. Questionnaire Fatigue Severity Scale (FSS) can be used to measure the degree of fatigue, both in the normal population and in those with severe neurologic disorder in various health facilities. Assessment is carried out to see the relationship of fatigue to motivation, activity, physical function, carrying out tasks, distractions to work, family and social life $\mathrm{e}^{10,11}$.

MG is a chronic disease and lasts for a long time so that health services focus on hindering progression, management of symptoms and severity of disease and improve the quality of $\mathrm{MG}$ patient life $^{12}$. Assessment of the severity of disease in MG patients is very important because it is the main parameter of disease management outcomes $\mathrm{MG}^{13}$. Measurement of the severity of the disease can be done using Myasthenia Gravis Composite (MGC) score recommended by MGFA for use in MG research. The MGC scale has advantages of being simpler and combining patient history and examination by a clinician ${ }^{14}$.

Growing evidence reports that fatigue has a negative impact on disease severity ${ }^{15}$. However, the literature on fatigue in MG is still lacking rare and the relationship between the level of fatigue with the severity of the disease MG patients is not known. Therefore, the researchers tried to conduct a study to determine the relationship between the level of fatigue measured using FSS with the degree of disease severity as measured by MGC in MG patients.

\section{Materials and Methods}

This study was an analytical observational study with a cross-sectional approach myasthenia gravis patients, who were in the neurology clinic Dr. Soetomo Public Hospital Surabaya. The data collected covers a period of 3 months from April to June 2021. The primary data used in this study include: (1). age, (2). gender, (3). age at onset, (4). Fatigue Severity Scale (FSS) and (5) Myasthenia Gravis Composite (MGC) Score The inclusion criteria in this study were patients with myasthenia gravis who have visited Neurology Clinic Dr. Soetomo Hospital with current age over 18 years.

The fatigue level of the studied myasthenia gravis patients was assessed using Fatigue Severity Scale (FSS). The FSS assessment is divided into: (a) mean score $<4$ : mild fatigue and (b) Mean score $\geq 4$ : severe fatigue. The MGC score is divided into: (a) score $<4$ : mild status severity and (b) score $\geq 4$ : severe status severity. Age at onset was classified into early onset $<$ 50 years and late-onset $\geq 50$ years. 
The collected data was analyzed using the Statistical Package for the Social Sciences (SPSS) v22 for Windows (IBM Inc., Chicago, IL). Chi-square test with the calculation of odds ratio (OR) and $95 \%$ confidence interval was used to determine association with considered statistically significant when the value was $\mathrm{p}<0.05$.

\section{Results}

The total number of research subjects analyzed were 37 subjects. Demographic characteristics based on age, the youngest age of the subject was 20 years old and the oldest 68 years old, with a mean age of the study subjects $45.03 \pm 11.69$ years. Based on the age of onset MG symptoms, the age of onset the earliest age is 16 years, while the last onset age is 66 year. Based on gender, male 14 subjects $(37.8 \%$ ), while female 23 subjects $(62.2 \%)$. Furthermore, the research subjects obtained with severe FSS 24 subjects (64.9\%) and mild FSS 13 subjects (35.1\%). The average value of the FSS is 4.02 \pm 1.93 . A total of $22(58.5 \%)$ subjects had moderatesevere MGC and 15 (41.5\%) subjects had mild MGC. Score the average total MGC was $5.24 \pm 5.64$. (table 1).

Table 1. Demography data of participants

\begin{tabular}{|c|c|c|c|}
\hline & Total (\%) & Mean & Std. Deviation \\
\hline $\begin{aligned} & \text { Age } \\
&<50 \mathrm{yrs} \\
& \geq 50 \mathrm{yrs}\end{aligned}$ & $\begin{array}{l}23(62,2) \\
14(37,8)\end{array}$ & 45,03 & 11,69 \\
\hline $\begin{array}{l}\text { Gender } \\
\text { Male } \\
\text { Female }\end{array}$ & $\begin{array}{l}14(37,8) \\
23(62,2)\end{array}$ & & \\
\hline $\begin{array}{l}\text { Age at onset } \\
<50 \mathrm{yrs} \\
\geq 50 \mathrm{yrs}\end{array}$ & $\begin{array}{c}28(75,7) \\
9(24,3)\end{array}$ & 40,38 & 12,60 \\
\hline $\begin{array}{c}\text { Fatigue Level } \\
\text { FSS }<4 \\
\text { FSS } \geq 4\end{array}$ & $\begin{array}{l}13(35,1) \\
24(64,9)\end{array}$ & 4,02 & 1,93 \\
\hline $\begin{array}{c}\text { Disease severity } \\
\text { MGC }<4 \\
M G C \geq 4\end{array}$ & $\begin{array}{l}15(41,5) \\
22(58,5)\end{array}$ & 5,24 & 5,64 \\
\hline
\end{tabular}

Table 2 shows that there were 18 subjects (75\%) with Severe FSS with moderate to severe disease and 6 subjects with Severe FSS (25\%) had mild disease severity, whereas 4 subjects $(30,8 \%)$ with mild FSS had moderate to severe disease severity and 9 subjects (69,2\%) with mild FSS had mild disease severity.
There was a significant relationship between the level of fatigue (FSS) and the degree of disease severity $(\mathrm{MGC})$ and statistically significant with $\mathrm{p}$ value $=0.009$ and $\mathrm{OR}=6.75(95 \%$ CI 1.51-30.16) which means the level of fatigue (FSS) is increasing 6.75 times the risk of experiencing moderate to severe disease severity. 
Table 2. The chi-square analysis test between FSS and MGC

\begin{tabular}{|c|c|c|c|c|}
\hline \multirow{2}{*}{ Fatigue Level (FSS) } & \multicolumn{2}{|c|}{ Disease Severity (MGC) } & \multirow{2}{*}{ p value } & \multirow{2}{*}{ 95\% Confidence Interval } \\
\cline { 2 - 3 } & Moderate-Severe & Mild & & \\
\hline FSS $\geq 4$ & 18 & 6 & & $($ OR 6,750$)$ \\
FSS $<4$ & 4 & 9 & 0.009 & $95 \%$ CI $(1,51-30,16)$ \\
\hline Total & 22 & 15 & & \\
\hline
\end{tabular}

\section{Discussion}

This research is an analytic observational study with cross sectional design to determine the relationship between the level of fatigue with the severity of MG disease. Sampling has done with consecutive sampling from April to June 2021 at the Neurology Clinic. The sample size is determined by the formula sample size for unpaired categorical analytic research, the value of proportion effect in case group (p1) and control group (p2) was determined based on previous research and obtained a minimum sample size 32 people. The sample size obtained in this study was 37 samples. Statistical analysis using IBM SPSS software version 22.0. Research data analyzed by Chi Square test. This research has limitations because did not analyze the MG type variable based on the type of antibody found as confounding variable due to no routine examination of antibody levels in myasthenia gravis patients.

The demographic data of the research subjects included age and gender. Then, analyzing relationship between age and sex with the severity of MG disease. Characteristics based on demographic data obtained the youngest age of the subject study was 20 years old and the oldest was 66 years with a mean age of $45 \pm$ 11,694 . There was no significant relationship between the patient's age and the severity of the disease. Subjects with male 14 subjects (37.8\%), while women were 23 subjects $(62.2 \%)$ with a ratio of female : male $=3: 2$, which is based on statistical analysis also not found a significant relationship between gender and the degree of disease severity. The results of this study are in accordance with the study by Fan et al. at $985 \mathrm{MG}$ patients, the mean age of the study subjects was 40.8 years with a ratio of 3:1 women are more affected than men. This demographic data is similar with the study by Zhang et al. which mentions the ratio of women: men of 3:1 at the age of $<40$ years, then balanced at the age of 40-50 years and more about men aged $>50$ years. Sex hormones play a role in predisposition to MG and involvement of the hormone estrogen causes thymic hyperplasia thereby increasing the risk of developing $\mathrm{MG}$, especially early-onset $\mathrm{MG}^{16}$.

Citarak, et al. in his research stated that age and gender has no effect on the clinical degree of disease and the total value of the patient's muscle strength myasthenia gravis. When age and sex are related to clinical grade disease, there was no difference in the clinical severity score between women and men and the age of patients who are less than 50 years more than equal to 50 years. Only mentioned in the study that muscle weakness is more severe in men 50 years of age compared to younger men and women 50 years of age. This research according to research by Citarak et al. above which is likely caused by the relatively homogeneous age of the subjects of this study, i.e. most of the are in the young adult range $(<50 \text { years })^{17}$.

In this study the authors linked the age of onset of MG symptoms with the severity of MG disease. Obtained research subjects with age the earliest onset of MG symptoms was 16 years, while the age of symptom onset was late at age 66 years with a mean age 
of symptom onset of study subjects $40.4 \pm 12.6$ years. Bivariate data analysis showed that age of symptom onset as confounding variables did not find a significant relationship to the degree of MG disease severity. The relationship between the level of fatigue (FSS) with the degree MG disease severity was analyzed in this study. Subject research with severe FSS 24 subjects (64.9\%) and mild FSS 13 subjects (35.1\%), which based on bivariate analysis showed that the level of fatigue (FSS) has a significant relationship with the severity disease (MGC) both clinically and statistically. The results of this study are not in accordance with the study conducted by Zivkovic et al. who concluded that late-onset patients were associated with the presence of thymoma and are more severe and more difficult to treat. Thymoma is often associated with an autoimmune process. Neoplastic epithelial cells in thymoma expresses several antigenlike antibodies that attack acetylcholine receptors, the muscle protein titin and ryanodine that cause more severe $\mathrm{MG}^{18}$. The study by Ruiter et al. reported that the fatigue scores are associated with more severe disease severity measured by MGC, QMG, MGII and MG-ADL. Muscle fatigability related to the pathogenesis of $\mathrm{MG}$ and the patient's perception of fatigue play a role in increasing the severity of the disease ${ }^{3}$.

\section{Conclusions}

Analysis of the chi-square test showed that the variable affecting diasease severity in patients myasthenia gravis was the fatigue level. Patients with severe fatigue were 6,75 times more likely to experience severe disease status than patients with mild fatigue. Therefore, patients and clinicians should be more careful in managing fatigue in mysthenia gravis patients.

Author Contributions: Conceptualization, D.P., F. and M.H.; methodology, F. and M.H.; software, D.P.; validation, D.P., F. and M.H.; formal analysis, D.P.; investigation, D.P. and F.; resources, F. and M.H..; data curation, D.P.; writing - original draft preparation, D.P.; writing - review and editing, F. and M.H...; visualization, D.P..; supervision, F. and M.H.; project administration, D.P.; funding acquisition D.P., F. and
M.H. All authors have read and agreed to the published version of the manuscript.

Funding: This research was carried out through individual funding.

Institutional Review Board Statement: This study received an ethical clearance from Dr. Soetomo Public Hospital.

Informed Consent Statement: Informed consent was obtained from all subjects involved in the study.

Data Availability Statement: Data sharing not applicable

Acknowledgments: none

Conflicts of Interest: The authors declare no conflict of interest.

\section{References}

1. Gilhus NE, Socrates T, Amelia E, Jacqueline P, Burns TM. Myasthenia gravis (Primer). Nature Reviews Disease Primers. 2019;5(1). DOI:10.1038/ s41572-019-0079-y

2. Badan Penelitian dan Pengembangan Kesehatan Kementerian Kesehatan RI. (2010). Riset Kesehatan Dasar RISKESDAS 2010

3. Ruiter AM, Verschuuren JJ, Tannemaat MR. Fatigue in Patients with Myasthenia Gravis. A Systematic Review of the Literature. Neuromuscular Disorders. 2020 Jul 1. DOI:10.1016/j.nmd.2020.06.010

4. Godoy DA, Mello LJ, Masotti L, Napoli MD. The myasthenic patient in crisis: an update of the management in Neurointensive Care Unit. Arquivos de Neuro-Psiquiatria. 2013 Sep;71(9A):627-39. DOI: 10.1590/0004-282X20130108

5. Landfeldt E, Pogoryelova O, Sejersen T, Zethraeus N, Breiner A, Lochmüller H. Economic Costs of Myasthenia Gravis: A Systematic Review. PharmacoEconomics. 2020 Jul;38(7):715-28. DOI: 10.1007/s40273-020-009128

6. Hoffmann S, Ramm J, Grittner U, Kohler S, Siedler $\mathrm{J}$, Meisel A. Fatigue in myasthenia gravis: risk factors and impact on quality of life. Brain and behavior. 2016 Oct;6(10):e00538. DOI: 10.1002/ brb3.538 
7. Penner IK, Paul F. Fatigue as a symptom or comorbidity of neurological diseases. Nature Reviews Neurology. 2017 Nov;13(11):662. DOI: 10.1038/nrneurol.2017.117

8. Bhat S, Chokroverty S. Fatigue in neurologic disorders. Sleep Medicine Clinics. 2013 Jun 1;8(2):191-212. DOI : 10.1016/j.jsmc.2013.02.006

9. Kluger BM, Krupp LB, Enoka RM. Fatigue and fatigability in neurologic illnesses: proposal for a unified taxonomy. Neurology. 2013 Jan 22;80(4):409-16. DOI: 10.1212/ WNL.0b013e31827f07be

10. Valko PO, Bassetti CL, Bloch KE, Held U, Baumann CR. Validation of the fatigue severity scale in a Swiss cohort. Sleep. 2008 Nov 1;31(11):1601-7. DOI: $10.5167 /$ uzh-10609

11. Tugwell P, Idzerda L, Wells GA. Generic qualityof-life assessment in rheumatoid arthritis. The American journal of managed care. 2008 Apr 1;14(4):234-.

12. Siderowf A, Xie SX, Hurtig H, Weintraub D, Duda J, Chen-Plotkin A, Shaw LM, Van Deerlin V, Trojanowski JQ, Clark C. CSF amyloid $\beta$ 1-42 predicts cognitive decline in Parkinson disease. Neurology. 2010 Sep 21;75(12):1055-61. DOI: 10.1212/WNL.0b013e318258f744
13. Stojanov A, Miloševic V, Đordevic G, Stojanov J. Quality of life of myasthenia gravis patients in regard to epidemiological and clinical characteristics of the disease. The neurologist. 2019 Jul 1;24(4):11520. DOI: $10.1097 /$ NRL.0000000000000238

14. Basta IZ, Pekmezović TD, Perić SZ, KisićTepavčević DB, Rakočević-Stojanović VM, Stević ZD, Lavrnić DV. Assessment of health-related quality of life in patients with myasthenia gravis in Belgrade (Serbia). Neurological Sciences. 2012 Dec;33(6):1375-81. DOI: 10.1007/s10072-012$1170-2$

15. Alekseeva TM, Gavrilov YV, Kreis OA, Valko PO, Weber KP, Valko Y. Fatigue in patients with myasthenia gravis. Journal of neurology. 2018 Oct;265(10):2312-21. DOI: 10.1007/s00415-0188995-4

16. Fan L, Ma S, Yang Y, Yan Z, Li J, Li Z. Clinical differences of early and late-onset myasthenia gravis in 985 patients. Neurological research. 2019 Jan 2;41(1):45-51.

17. Citirak G, Cejvanovic S, Andersen H, Vissing J. Effect of gender, disease duration and treatment on muscle strength in myasthenia gravis. PloS one. 2016 Oct 14;11(10):e0164092.

18. Živković SA, Clemens PR, Lacomis D. Characteristics of late-onset myasthenia gravis. Journal of neurology. 2012 Oct;259(10):2167-71. 